Revista Perspectivas Online: Biológicas \& Saúde

Dezembro de 2019, Vol. 9, n 31 , p.22-33

ISSN: 2236-8868 (Online)

DOI: $10.25242 / 886893120191880$

\title{
PERFIL EPIDEMIOLÓGICO DOS CASOS DE ARBOVIROSES DO MUNÍCIPIO DE CAMPOS DOS GOYTACAZES/RJ
}

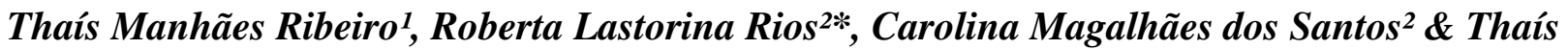 \\ Aparecida de Castro Palermo ${ }^{2}$
}

\section{RESUMO}

RIBEIRO, T. M.; RIOS. R. L.; SANTOS, C. M.; PALERMO, T. A. C. As arboviroses do município de Campos dos Goytacazes/RJ: do município ao paciente. Perspectivas Online: Biológicas \& Saúde, v. 9, n. 31, p. 22-33, 2019.

As arboviroses são um conjunto de doenças virais que infectam os seres humanos e outros animais pela picada de mosquito, sendo o Aedes aegypti o principal vetor no Brasil. Características como a imprevisibilidade, potencial transmissor epidemiológico, relação sutil ambiente versus comportamento humano, capacidade de prevenção e erradicação, tem colocado estas doenças nas principais discussões sobre problemas de saúde pública. Neste contexto, o presente estudo objetivou conhecer o perfil epidemiológico dos casos de arboviroses que ocorreram na população do município de Campos dos Goytacazes/RJ, bem como os principais bairros que registraram maior prevalência de distribuição de casos. Trata-se de uma pesquisa quantitativa e suas variáveis, descritivas, de corte transversal referentes ao ano de 2018. Das arboviroses registradas a de maior prevalência foi a chikungunya e com maior registro sobre indivíduos residentes na área urbana e do sexo feminino. A notificação compulsória dos casos é de extrema importância para caracterizá-la o cenário epidemiológico e priorizar esforços nas áreas mais vulneráveis. Se faz necessário mais estudos científicos relacionado às consequências dessas doenças a nível individual e coletivo a fim de serem desenvolvidas novas abordagens em saúde.

Palavras-chave: Dengue; Chikungunya, Zika, Febre amarela. 


\section{ABSTRACT}

Arboviruses are a set of viral diseases that infect humans and other animals by mosquito bites, with Aedesaegypti being the main vector in Brazil. Features such as unpredictability; epidemiological transmitting potential; Subtle environment relationship versus human behavior; prevention and eradication capacity, has put them in the main discussions on public health problems. In this context, the present study aimed to know the epidemiological profile of arbovirus cases that occurred in the population of Campos dos Goytacazes/RJ, as well as the main neighborhoods that recorded the highest prevalence of case distribution. It is a quantitative study and its descriptive variables, cross-sectional, referring to the year 2018. Of the most prevalent arboviruses recorded was chikungunya and with the highest prevalence among urban dwellers and females. Compulsory notification of cases is extremely important to characterize the epidemiological scenario and prioritize efforts in the most vulnerable areas. Further scientific studies regarding the consequences of these diseases at individual and collective level are needed in order to develop new health technologies.

Keywords: Dengue; Chikungunya, Zika, Yellow Fever.

\footnotetext{
${ }^{1}$ Institutos Superiores de Ensino do CENSA - ISECENSA - Graduanda do curso de Enfermagem - Rua Salvador Correa, 139, Centro, Campos dos Goytacazes, RJ, CEP: 28035-310, Brasil.

2 Institutos Superiores de Ensino do CENSA - ISECENSA Pesquisadora do Laboratório de Estudos em Saude Pública LAESP/ISECENSA - Rua Salvador Correa, 139, Centro, Campos dos Goytacazes, RJ, CEP: 28035-310, Brasil.

(*) e-mail: enf_roberta@hotmail.com

Data de recebimento: 24/09/2019. Aceito para publicação: 20/10/2019.
} 


\section{INTRODUÇÃOO}

As arboviroses são um conjunto de doenças virais que infectam os seres humanos e outros animais pela picada de artrópodes hematófagos, sendo o Aedes aegypti L. o principal vetor no Brasil. Os arbovírus que causam doenças em humanos e outros animais de sangue quente são membros de cinco famílias virais: Bunyaviridae, Togaviridae, Flaviviridae, Reoviridae $e$ Rhabdoviridae1 (LOPES et al., 2014).

Características como a imprevisibilidade, potencial transmissor epidemiológico explosivo à nível global, relação sutil ambiente versus comportamento humano, capacidade de prevenção e erradicação, tem colocado estas doenças nas principais discussões sobre problemas de saúde pública (LIMA-CAMARA, 2016).

De 2002 a 2011, as arboviroses se consolidaram como um dos maiores desafios a serem combatidos (VASCONCELOS et al., 2016). A dengue, por exemplo, vem acometendo os brasileiros desde 1986, entremeando estas quatro décadas com surtos epidêmicos a cada 3-5 anos quando acontece a introdução de novos sorotipos em áreas antes incólumes ou alteração do sorotipo predominante (LIMA, 2016).

Em 2015, o Zika vírus foi um vilão que chamou a atenção de todas as autoridades mundiais em controle de doenças infecciosas em decorrência do seu alto impacto sobre o desenvolvimento do sistema nervoso fetal, independe da idade gestacional em que ocorresse a contaminação. No último trimestre de 2016, a febre amarela assustou a região sudeste por evidenciar que a mesma não estava estagnada somente na transmissão entre macacos, fazendo com que um grande número de humanos fosse acometido por meio de transmissão silvestre (NUNES, 2016). Em 2014 ocorreu um surto do Chikungunya vírus, considerada então uma arbovirose emergente, tendo gerado um alerta em todo território, em especial no município de Campos dos Goytacazes/RJ, devido ao seu estilo incapacitante por artralgias intensas e persistentes, desenvolvendo caráter de cronicidade (SOUZA et al., 2016). Para se ter uma ideia, em 2018, o Rio de Janeiro já era o $3^{\circ}$ Estado com maior incidência de casos no Brasil, perdendo somente para o Mato Grosso e Minas Gerais (BRASIL, 2018).

Atualmente, outro fator de risco potencial, atribuído à emergência e reemergência das arboviroses, é a susceptibilidade da população brasileira, visto a ampla distribuição do vetor por toda a extensão territorial e a falta de tratamento específico e imunoprevenção eficaz (LIMACAMARA, 2016), mesmo diante dos esforços das autoridades em saúde, pesquisa e laboratórios envolvidos.

Segundo o Instituto Brasileiro de Excelência em Saúde (2016), a Organização PanAmericana de Saúde, por meio do seu Conselho Diretivo da OPAS, devem ser otimizados os aspectos de vigilância reforçada, detecção precoce de arboviroses emergentes e reemergentes, controle integrado, melhoria na detecção e diagnóstico e um melhor controle dos mosquitos vetores dessas doenças em todo o território nacional, por meio de uma abordagem integrada para a prevenção as arboviroses.

As arboviroses, bem como outras doenças tropicais negligenciadas, atuam em um "silêncio amordaçado" nos países em que há o predomínio de vulnerabilidades sociais, favorecendo a manutenção de desigualdades e de fatores limitantes ao desenvolvimento humano, reafirmando a necessidade de posicionamento social e gestor (OPAS, 2016).

Diante do exposto, este trabalho teve por objetivo conhecer o perfil epidemiológico dos casos de arboviroses que ocorreram na população do município de Campos dos Goytacazes/RJ, bem 
como os principais bairros que registraram maior prevalência de distribuição de casos.

\section{METODOLOGIA}

Trata-se de um estudo descritivo, quantitativo de corte transversal, realizado no setor de Vigilância Epidemiológica da Vigilância em Saúde no município de Campos dos Goytacazes/RJ.

O estudo foi formado por dados de domínio público referente às notificações compulsórias dos casos de doenças das arbovirose a partir do banco de dados municipal do Sistema de Informação de Agravos Nacional - SINAN. Como critério de inclusão neste estudo foram analisadas as notificações de casos suspeitos e positivos para as Dengue, Chikungunya, Zika e Febre Amarela detectadas no ano de 2018 e como critério de exclusão, as fichas de notificações de pacientes com endereço de residência distinto ao município de Campos dos Goytacazes/RJ.

Os dados após serem coletados a partir da plataforma do Sistema de Informação de Agravos de Notificação foram digitados no Excel e posteriormente, analisados com auxílio do software Statistical Package for the Social Sciences (SPSS), versão 24.0.

\section{RESULTADOS}

O total de casos notificados de arboviroses no Município de Campos dos Goytacazes/RJ foi de 8.892 para o ano de 2018.

Dentre as amostras analisadas, foram notificados 7.628 casos Chikungunya, 1.257 casos de dengue, 4 casos de Zika vírus e 3 casos de febre amarela (Figura 1). Considerando o número total de casos notificados em 2018, podemos verificar que a amostra foi predominantemente do sexo feminino nos casos de Chikungunya, dengue e Zika vírus (Figura 2).

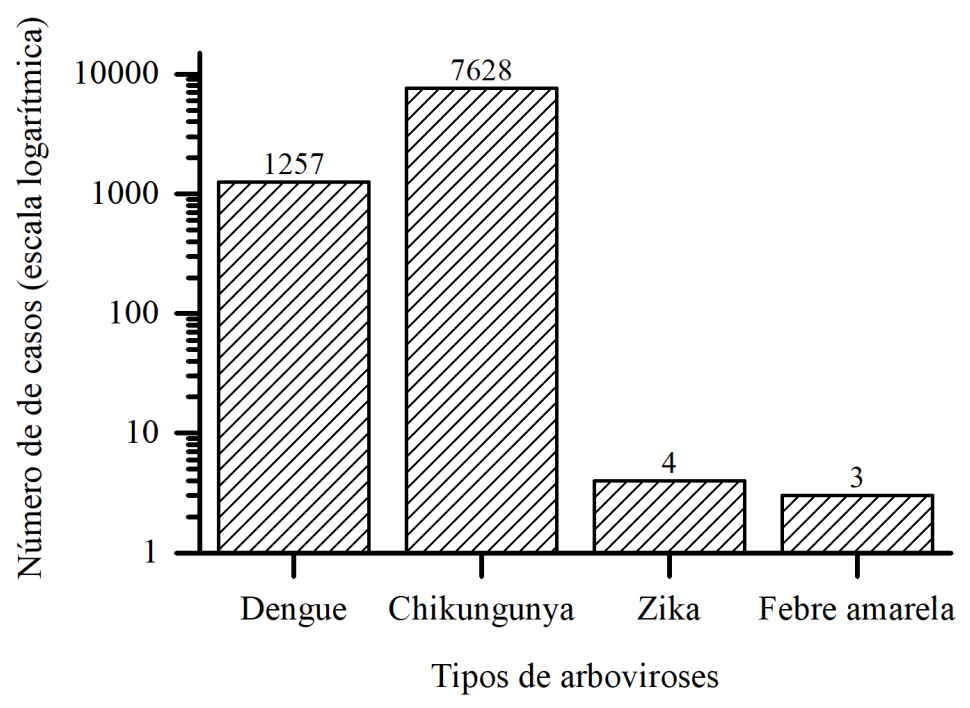

Figura 1: Número de casos notificados de incidência de arboviroses no município de Campos dos Goytacazes/RJ no ano de 2018. 


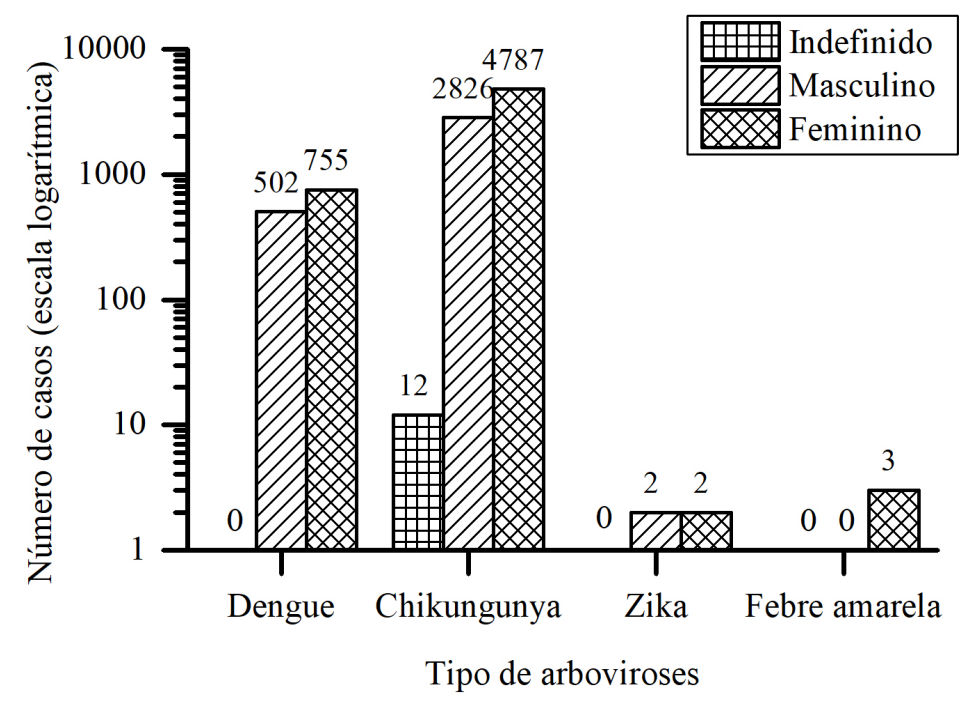

Figura 2: Caracterização da amostra por sexo, Campos dos Goytacazes/RJ 2018.

Quanto à distribuição do número de casos relacionado ao tempo de ocorrência, a Chikungunya teve predominância nos meses entre abril e setembro, enquanto a dengue entre março e junho (Figura 3).

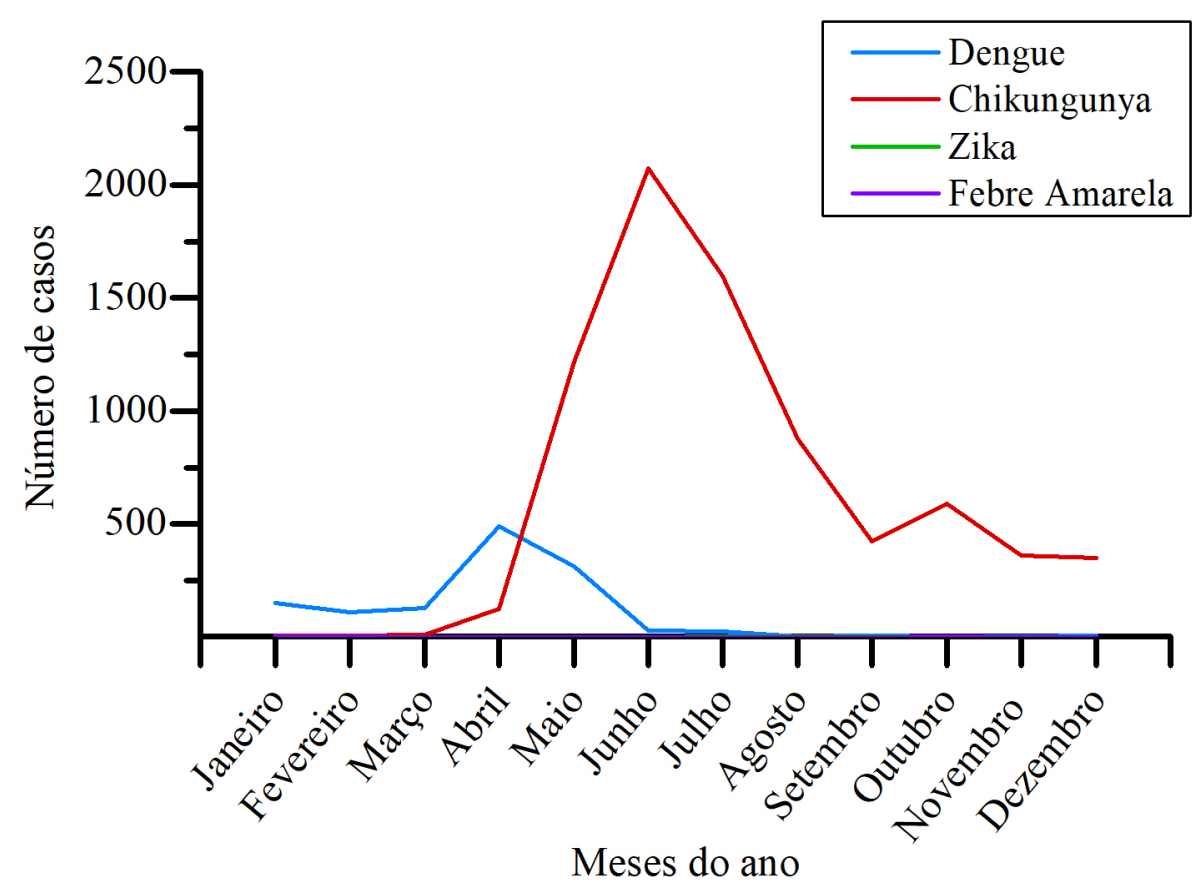

Figura 3: Distribuição da amostra de acordo com o mês, Campos dos Goytacazes/RJ 2018.

Quanto à distribuição demográfica dos casos notificados de dengue e Chikungunya, maior número de casos de dengue ocorreu no bairro Ponta da Lama e, de Chikungunya, nos bairros Mussurepe, Ponta da Lama e Travessão (Figura 4). Todos os demais bairros apresentaram número de casos de Chikungunya inferior a 250. Casos de Zika ocorreram nos seguintes bairros: Parque 
Cala Bouco (1), Parque do Rosário (1), Tocos (1) e Travessão (1). Já os casos suspeitos de Febre Amarela foram notificados no Parque São José (1) e no Parque Califórnia (1).
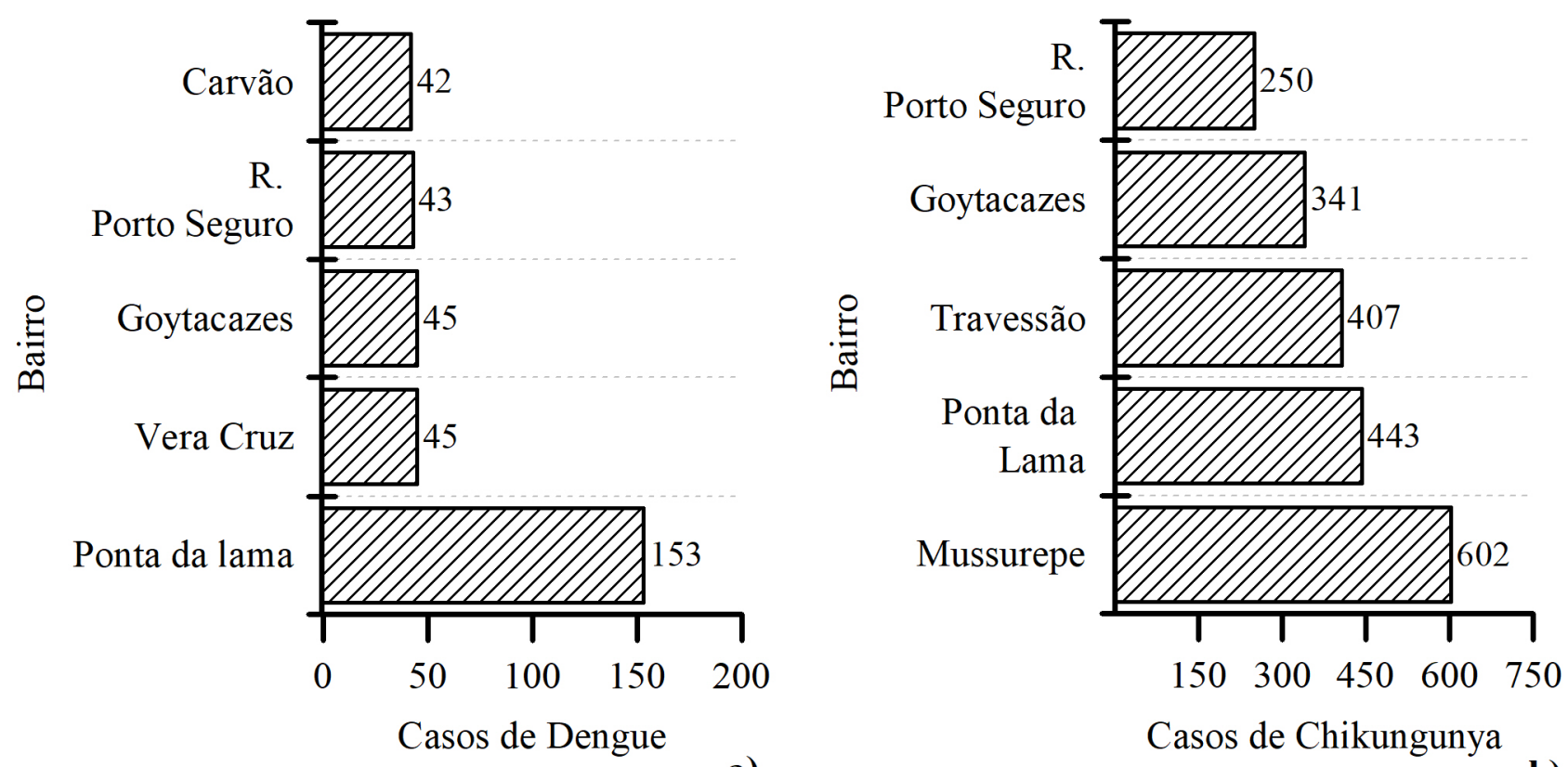

a)

Casos de Chikungunya

b)

Figura 4: Distribuição de casos de Dengue (a) e Chikungunya (b) por bairro, Campos dos Goytacazes/ RJ 2018.

A faixa etária com maior número de casos notificados foi para indivíduos adultos, população ativa (de 37 a 63 anos de idade), com média de idade nos casos de dengue, Chikungunya e Zika de 38 anos, enquanto para febre amarela a idade média foi de 63 anos de idade (Tabela 1).

Tabela 1: Distribuição dos casos de arboviroses notificados por idade no município de Campos dos Goytacazes (2018).

\begin{tabular}{lcccc}
\hline \multirow{1}{*}{ Agravos } & \multicolumn{4}{c}{ Idade } \\
& Média & Desvio Padrão & Mínima & Máxima \\
\hline Dengue & 38,16 & 18,96 & 0 & 104 \\
Chikungunya & 40,52 & 19,58 & 0 & 102 \\
Zika & 37,00 & 31,22 & 12 & 72 \\
Febre Amarela & 63,00 & 8,66 & 53 & 68 \\
\hline
\end{tabular}

Considerando a raça dos pacientes, a raça branca teve predomínio entre as doenças dengue e Chikungunya (Tabela 2). 
Tabela 2: Distribuição dos casos de arboviroses notificados por raça no município de Campos dos Goytacazes (2018)

\begin{tabular}{lcccc}
\hline \multirow{2}{*}{ Raça } & \multicolumn{3}{c}{ Agravos } \\
& Dengue & Chikungunya & Zika & Febre Amarela \\
\hline Amarela & 7 & 44 & 0 & 0 \\
Branca & 694 & 3022 & 2 & 0 \\
Parda & 139 & 1782 & 0 & 0 \\
Preta & 132 & 930 & 0 & 0 \\
Indígena & 0 & 6 & 0 & 0 \\
Ignorado & 285 & 1841 & 2 & 3 \\
\hline
\end{tabular}

A Tabela 3 mostra a notificação de 2 casos de Zika vírus em gestantes.

Tabela 3: Distribuição dos casos notificados por período gestacional (2018).

\begin{tabular}{lcccc}
\hline \multirow{2}{*}{ Período Gestacional } & \multicolumn{3}{c}{ Agravos } \\
& Dengue & Chikungunya & Zika & Febre Amarela \\
\hline Primeiro Trimestre & 0 & 0 & 0 & 0 \\
Segundo Trimestre & 3 & 0 & 1 & 0 \\
Terceiro Trimestre & 0 & 0 & 1 & 0 \\
\hline
\end{tabular}

A Tabela 4 mostra o predomínio das notificações em zona urbana.

Tabela 4: Distribuição dos casos notificados por zona residencial (2018).

\begin{tabular}{lcccc}
\hline \multirow{2}{*}{$\begin{array}{l}\text { Zona } \\
\text { Residencial }\end{array}$} & Dengue & Chikungunya & Zika & $\begin{array}{c}\text { Febre } \\
\text { Amarela }\end{array}$ \\
\hline Rural & 16 & 56 & 0 & 0 \\
Periurbana & 0 & 4 & 0 & 0 \\
Urbana & 566 & 6655 & 4 & 0 \\
Ignorado & 28 & 38 & 0 & 3 \\
\hline
\end{tabular}

Ao analisarmos a sintomatologia, nos casos de dengue e chikungunya os sinais e sintomas são muito semelhantes. Na Figura 5, são apresentados os casos de dengue no qual houve predomínio de sinais de dor retroorbital, artralgia, cefaleia, náusea, vômito, mialgia e febre e, na Figura 6, os casos de chikungunya com sinais iguais aos da dengue, diferenciando pela presença de exantema, artrite e dores nas costas. 


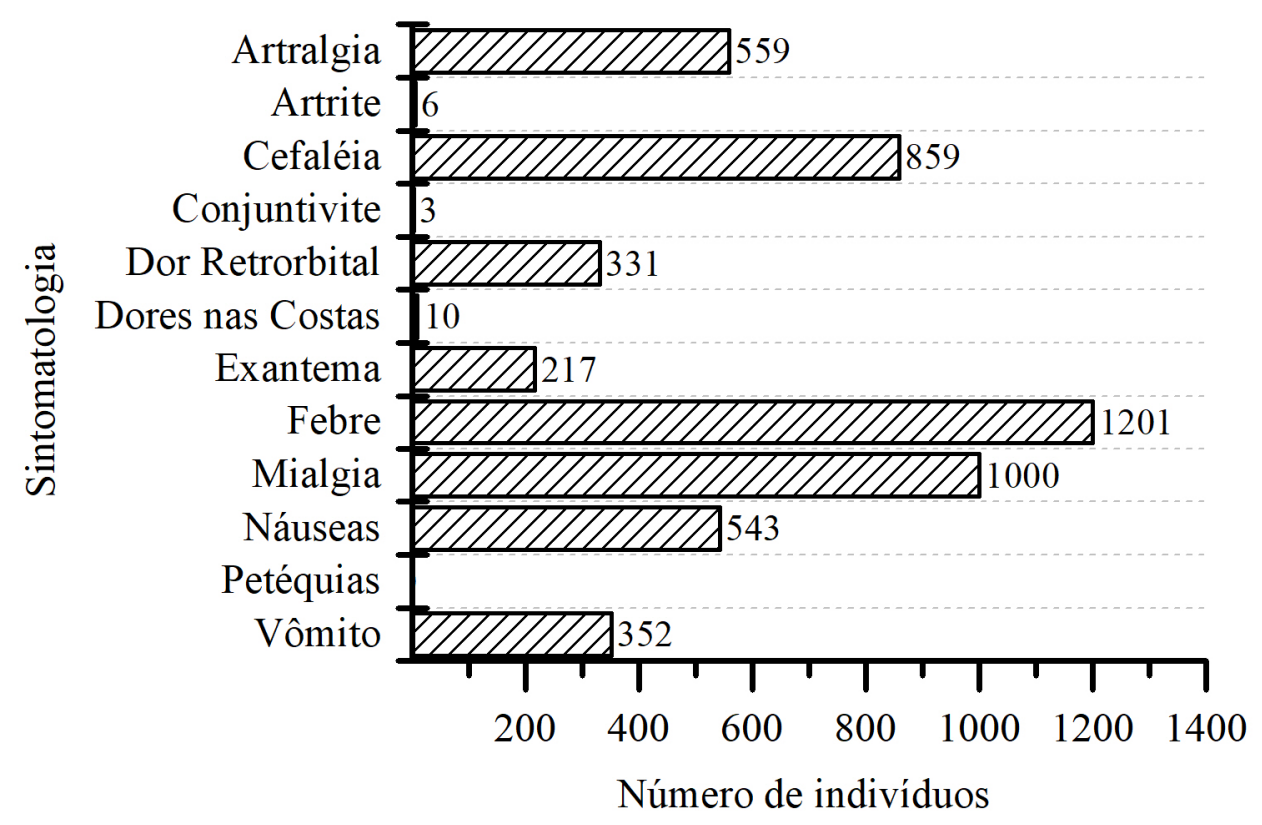

Figura 5: Sintomatologia dos casos de Dengue. Campos dos Goytacazes/ RJ 2018.

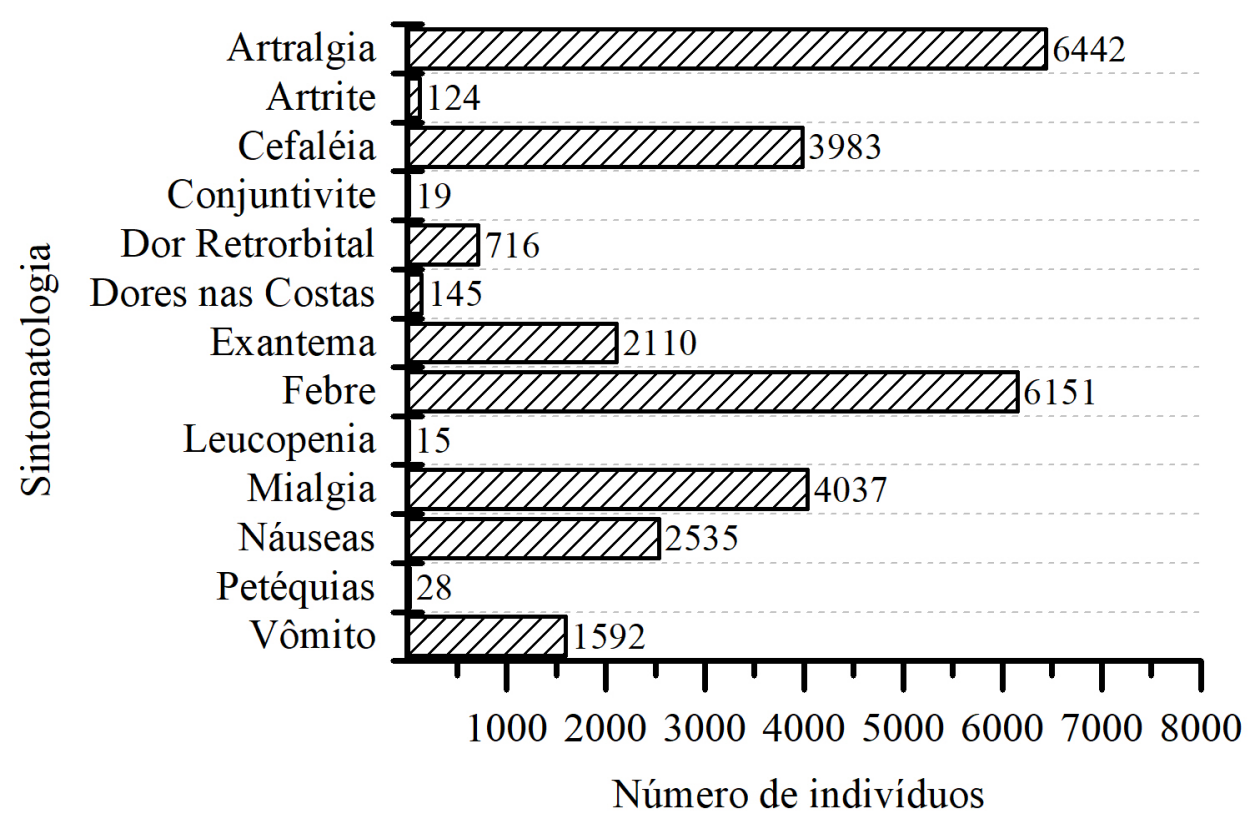

Figura 6: Sintomatologia dos casos de Chikungunya. Campos dos Goytacazes/RJ 2018.

\section{DISCUSSÃO}

No presente estudo, verificou-se o registro de 8.892 casos notificados em 2018 no município de Campos dos Goytacazes com predominância de acometimento na faixa etária de pacientes entre 37 e 63 anos. Na análise da variável sexo, houve prevalência do sexo feminino sobre o masculino. 
A predominância dos casos no sexo feminino pode ser explicada pela maior exposição ao vetor devido às mulheres permanecerem período maior de tempo em domicílio do que os homens.

As arboviroses são de grande significância na saúde pública devido vários fatores, como a diversidade de agentes infecciosos envolvidos e a abundância de manifestações clínicas, a ausência de medidas imunoprofiláticas e a dificuldade na implementação e manutenção de medidas educativas e sanitárias. Atualmente, no Brasil, as arboviroses que apresentam maior circulação são a Dengue, o Chikungunya a Febre Amarela e o Zika (DONALISIO et al, 2017).

De acordo com dados do boletim epidemiológico, foram registrados 290.889 casos prováveis de dengue, Chikungunya e Zika no país, no período de 30/12/2018 a 23/03/2019. Em 2018, no mesmo período, foram registrados 100.858 casos prováveis (BRASIL, 2019).

Neste estudo houve definição de áreas de maior incidência no município, cujo bairro Ponta da Lama apresentou maior número de casos de dengue enquanto o bairro Mussurepe apresentou maior número de casos de Chikungunya. A estratificação do espaço constitui um importante instrumento de apoio para planejamento de ações de controle das arboviroses.

Em relação a sintomatologia, o estudo evidenciou a prevalência de febre nos casos de dengue e Chikungunya. A infecção por Chikungunya vírus produz um estado febril de início súbito e debilitante. Páscoa (2018) diz em seu estudo que a artralgia pode afetar até $80 \%$ dos pacientes e persiste durante meses e até mesmo anos, o que interfere na qualidade de vida do indivíduo, com impactos econômicos significativos, devido à redução da produtividade afetando a maioria na população ativa (20-60 anos). Além disso, causa doença neurológica em idosos e neonatos, podendo ser fatal. A gravidade da Chikungunya em recém-natos e o ônus da paralisia cerebral requerem medidas preventivas e terapêuticas, que devem ser precedidas de confirmação da viremia materna.

Sabe-se que a prevalência de doenças reumáticas, principalmente as artrites, aumentam com a idade. Os fatores de risco na faixa etária na qual se identificou maior risco foi aquela considerada economicamente ativa, entre 20 a 39 anos, sendo um dado importante para a vigilância epidemiológica, pois o espectro clínico da doença pode variar com casos graves entre pacientes com comorbidades, idosos e crianças (FLAYSINO, 2009).

Essa relação diretamente proporcional entre idade do paciente e intensidade da manifestação articular também foi encontrada em outros estudos. É relatado também possível diminuição da expectativa de vida em casos de idosos (PÁSCOA et al., 2018).

A dengue ainda é a doença que causa a maior perturbação devido às altas taxas de mortalidade que ela implica à população, assim como a incapacidade que a Chikungunya desencadeia ao indivíduo e as graves consequências neurológicas resultantes de complicações da Zika (TERRA et al., 2017).

Além disso, a extrema complexidade da interação entre o hospedeiro, reservatórios e vetores, na maioria dos casos pouco conhecida, por si só já é um grande desafio. Campanhas de educação sanitária precisam ser constantes e a vigilância deve ser reforçada como parte de programas eficazes de controle das doenças em humanos e animais domésticos, além da essencial minimização da participação de vetores.

Desde 2015 foram confirmadas crianças com microcefalia ou alterações sugestivas de infecção congênita causada pelo vírus Zika (PÁSCOA et al., 2018). Neste estudo, houve 02 casos confirmados de Zika no ano de 2018 na cidade de Campos dos Goytacazes. A epidemia da "síndrome congênita do Zika" engloba casos de microcefalia e/ou outras alterações do Sistema 
Nervoso Central associados à infecção pelo vírus que rompe a proteção da barreira hematoencefálica podendo causar a microcefalia na criança durante a gestação. As notificações de Zika em gestantes são muito importantes, para reconhecer a doença previamente e acompanhar essa gestante com mais cautela, contando também com o serviço epidemiológico.

Dessa forma, os sistemas de informação foram desenvolvidos para a coleta e processamento dos dados sobre os agravos de notificação, fornecendo informações para a análise do perfil da população adoecida, contribuindo para a tomada de decisões nos níveis municipal, estadual e federal.

\section{CONCLUSÕES}

No ano de 2018 houve o registro de 8.892 casos notificados, sendo a maior contaminação na população branca $(41,8 \%)$; em pacientes do sexo feminino $(62,4 \%)$ e 5 ocorrências em gestantes. Os dados revelaram uma ascensão na incidência de Chikungunya com um número de 7.628 casos notificados, seguido de dengue e Zika. No período, não houve referência à doença de febre amarela.

As arboviroses tiveram ampla prevalência no ambiente urbano $(81,2 \%)$ sendo o bairro de Ponta da Lama mais acometido por dengue e secundariamente por Chikungunya, com período temporal de máxima de infectibilidade em abril para dengue e junho para Chikungunya. Com informações de georeferenciamento é possível direcionar esforços nas áreas mais vulneráveis, facilitando assim a monitorização da circulação viral, identificação e eliminação de criadouros, bem como ações educativas a fim de sensibilizar a população da importância, desencadeando melhorias na qualidade das ações da vigilância em saúde frente ao quadro endêmico das arboviroses que a cada ano impacta a saúde coletiva a partir das transformações ambientais.

A notificação compulsória dos casos é de extrema importância e a insuficiência de preenchimento das Fichas de Notificação prejudicam as caracterizações dos cenários epidemiológicos. Sabe-se que por serem doenças com sinais e sintomas precoces semelhantes a tantos casos virais, este pode ser um fator agravante a possíveis não preenchimentos de tais fichas.

Neste estudo, a faixa etária mais acometida é a adulta, ocasionando deficiência na produtividade da população. É preciso ressaltar a necessidade de mais estudos científicos e pesquisas relacionadas às consequências dessas doenças a nível individual (em eventos graves neurológicos) e coletivo, incluindo o estudo da patogenicidade da doença, a interação entre os diversos vírus, a correlação com as doenças de base, a biologia e genética viral, a influência do meio e do clima e por fim incluir o desenvolvimento de novas tecnologias em saúde, como por exemplo, vacinas contra Chikungunya e Zika.

\section{REFERENCIAS}

BRASIL. Ministério da Saúde. Secretaria de Vigilância em Saúde. Monitoramento dos casos de dengue, febre de chikungunya e febre pelo vírus Zika até a Semana Epidemiológica 10 de 2018. Boletim Epidemiológico, Brasília, v. 49. n. 13, 2018. Disponível em: $<$ http://portalarquivos2.saude.gov.br/images/pdf/2018/abril/06/2018-012.pdf>. Acesso em: $18 / 06 / 2018$. 
BRASIL. Ministério da Saúde. Secretaria de Vigilância em Saúde. Monitoramento dos casos de dengue, febre de chikungunya e febre pelo vírus Zika até a Semana Epidemiológica 13 de 2019. Boletim Epidemiológico, Brasília, v. 50, n. 13, 2019. Disponível em:<http://portalarquivos2.saude.gov.br/images/pdf/2019/abril/30/2019-013-Monitoramento-doscasos-de-arboviroses-urbanas-transmitidas-pelo-Aedes-publicacao.pdf> Acesso em: 09/06/2019.

DONALISIO, M.R.; FREITAS, A.R.R.; ZUBEN, A.P.B.V. Arboviroses emergentes no Brasil: desafios para a clínica e implicações para a saúde pública. Rev. Saúde Pública, São Paulo, v. 51, 30, 2017. Disponível em: <http://dx.doi.org/10.1590/s1518-8787.2017051006889>. Acesso em: $18 / 06 / 2019$.

FLAUZINO, R. F.; SOUZA-SANTOS, R.; OLIVEIRA, R. M. Dengue, geoprocessamento e indicadores socioeconômicos e ambientais: um estudo de revisão. Revista Panamericana de Salud Pública, v. 25, p. 456-461, 2009. Disponível em: <https://www.doi.org/10.1590/S102049892009000500012>. Acesso em: 18/06/2018.

INSTITUTO BRASILEIRO DE EXCELÊNCIA EM SAÚDE. OPAS avança em nova estratégia de controle as arboviroses, incluindo zika vírus. 2016. Disponível em: <http://www.ibes.med.br/opasavanca-em-nova-estrategia-de-controle-de-arboviroses-incluindo-o-zika-virus/ $>$. Acesso em $18 / 06 / 2018$.

LIMA-CAMARA, T. N. Arboviroses emergentes e novos desafios para a saúde pública no Brasil. Rev. Saúde Pública. v. 50. n. 36. p. 1-7, 2016. Disponível em: <http://dx.doi.org/10.1590/S15188787.2016050006791>. Acesso em: 18/06/2018.

LIMA, G. R. V. B.; NASCIMENTO, I. A. T.; SILVA, M. E. V. VASCONCELOS, S. N.; SILVA, Y. M. O. Prevalência de Dengue no Município de Caruaru, Agreste Meridional de Pernambuco. In: CONGRESSO DA SOCIEDADE BRASILEIRA DE MEDICINA TROPICAL, 52, 2016, Maceió. Anais. Maceió, 2016. Disponível em: <http://www.sbmt.org.br/medtrop2016/wpcontent/uploads/2016/11/8332-Prevale\%CC\%82ncia-de-Dengue-no-Munici\%CC\%81pio-de-

Caruaru-Agreste-Meridional-de-Pernambuco.pdf>. Acesso: 18/06/2018.

LOPES, N.; NOZAWA, C.; LINHARES, R. E. C. Características gerais e epidemiologia dos arbovírus emergentes no Brasil. Rev. Pan-Americana de Saúde. v. 5, n. 2, p. 55-64, 2014. Disponível em: < http://dx.doi.org/10.5123/S2176-62232014000300007 >. Acesso em: 17/06/2018.

NUNES, J.; PIMENTA, D. A epidemia de Zika e os limites da saúde global. Lua Nova: Revista de Cultura e Política, n. 98, p. 21-46, 2016. Disponível em: <https://doi.org/10.1590/0102-6445021046/98>. Acesso em: 10/11/2017.

OPAS - ORGANIZAÇÃO PAN-AMERICANA DE SAUDE. Nova publicação da OPAS mostra progressos e desafios na eliminação de 11 doenças infecciosas negligenciadas nas Américas. OPAS-Brasil. $2016 . \quad$ Disponível em: $<$ http://www.paho.org/bra/index.php?option=com_content\&view=article\&id=5262:novapublicacao-da-opas-mostra-progressos-e-desafios-na-eliminacao-de-11-doencas-infecciosasnegligenciadas-nas-americas \&Itemid $=812>$. Acesso em: 10/11/2017.

PÁSCOA, F.R.B. et al. Análise da consistência dos bancos de dados das arboviroses em uma Unidade de Saúde em Fortaleza - CE. R. Saúd. Digi. Tec. Edu., Fortaleza, v. 3, n. especial, p. 1831, 2018. Disponível em: <http://www.periodicos.ufc.br/resdite/article/view/39698/95683 >. Acesso em: 18/06/2018. 
SOUZA, L. J. Perfil epidemiológico dos pacientes com evolução subaguda e crônica de infecção por Chikungunya vírus. In: CONGRESSO DA SOCIEDADE BRASILEIRA DE MEDICINA TROPICAL, 52, 2016, Maceió. Anais. Maceió, 2016. Disponível em: <http://www.sbmt.org.br/medtrop2016/wp-content/uploads/2016/11/8492-Perfil-epidemiológicodos-pacientes-com-evolução-subaguda.pdf>. Acesso em 18/06/2018.

TERRA, M. R., DA SILVA, R. S., PEREIRA, M. G. N., \& LIMA, A. F. Aedes aegypti e as arbovíroses emergentes no Brasil. Revista Uningá Review, v. 30, n. 3, 2017. Disponível em: $<$ http://revista.uninga.br/index.php/uningareviews/article/view/2028>. Acesso em: 18/06/2018.

VASCONCELOS, S. N., LIMA, G. R. V. B.; SILVA, M. E. V.; DO NASCIMENTO, I. A. T.; DA SILVA, Y. M. O. Dados Epidemiológicos do Surto de Arboviroses na IV Geres do Estado de Pernambuco de 2015 a 2016. In: CONGRESSO DA SOCIEDADE BRASILEIRA DE MEDICINA TROPICAL, 52, 2016, Maceió. Anais. Maceió, 2016. Disponível em: <http://www.sbmt.org.br/medtrop2016/wp-content/uploads/2016/11/8821-Dados-

Epidemiolo\%CC\%81 gicos-do-Surto-de-Arboviroses...pdf >. Acesso em 18/06/2018. 